\title{
Stochastic C-GNet Environment Modeling and Path Planning Optimization in a Narrow and Long Space
}

\author{
Jianjian Yang $\mathbb{D}^{\mathrm{D}}$, Zhiwei Tang, Xiaolin Wang, Zirui Wang, Biaojun Yin, and Miao Wu \\ School of Mechanical Electronic and Information Engineering, China University of Mining and Technology, Beijing 100083, China \\ Correspondence should be addressed to Jianjian Yang; yangjiannedved@163.com
}

Received 5 January 2018; Revised 26 April 2018; Accepted 16 May 2018; Published 19 June 2018

Academic Editor: Salvatore Alfonzetti

Copyright (C) 2018 Jianjian Yang et al. This is an open access article distributed under the Creative Commons Attribution License, which permits unrestricted use, distribution, and reproduction in any medium, provided the original work is properly cited.

\begin{abstract}
This study proposes a novel method of optimal path planning in stochastic constraint network scenarios. We present a dynamic stochastic grid network model containing semienclosed narrow and long constraint information according to the unstructured environment of an underground or mine tunnel. This novel environment modeling (stochastic constraint grid network) computes the most likely global path in terms of a defined minimum traffic cost for a roadheader in such unstructured environments. Designing high-dimensional constraint vector and traffic cost in nodes and arcs based on two- and three-dimensional terrain elevation data in a grid network, this study considers the walking and space constraints of a roadheader to construct the network topology for the traffic cost value weights. The improved algorithm of variation self-adapting particle swarm optimization is proposed to optimize the regional path. The experimental results both in the simulation and in the actual test model settings illustrate the performance of the described approach, where a hybrid, centralized-distributed modeling method with path planning capabilities is used.
\end{abstract}

\section{Introduction}

Environment modeling refers to the use of a unified form of expression to complete the environmental entity's own attributes and the internal structure of the entity model not only to describe the static attributes but also to express dynamic changes. The study on environment modeling for path planning at home and abroad mainly focuses on a mobile robot [1-4], mostly in an indoor or outdoor structural environment, such as an unmanned vehicle (e.g., rescue vehicles, exploration car, lunar rover, and Mars rover). Traditional environmental modeling methods mainly include V-Graph [5], T-Graph [6], and Voronoi [7] (e.g., space method, artificial potential field method [8], and approximate element decomposition method [9], such as topology graph and mathematical analysis class). These methods usually use external measurement to obtain the path planning of terrain two-dimensional coordinates and three-dimensional altitude information to establish digital terrain [10-13] and estimate its trafficability [14]. These traditional approaches solve the path planning problem to achieve two goals: shortest path [15-17] and obstacle avoidance demand [18]. However, in the face of an unstructured dynamic path environment formed by geological structure and stochastic dynamic generation, traditional space environment modeling should also consider topography and geology, pose adjustment cost, and walking constraints in addition to the realization of the shortest path planning target and obstacle avoidance.

Shi Meiping et al. [19] proposed a lunar surface multiconstraint modeling method, while Chen Cheng et al. [20] introduced a kind of a long-range polar robot environment modeling method. Pablo Urcola [21] et al. proposed a path planning method of a multirobot shortest path random terrain. Li Tiancheng et al. used a fan-shaped grid network to perform research robot path planning in a static environment. Traditionally, the existing network path model is established using the orthogonal grid. In these methods, the digital terrain is determined by considering the factors of motion constraint, system uncertainty, terrain availability, and so on. However, this method is generally applicable to the static structural environment model. Most of the roadway engineering paths are dynamically generated, and 


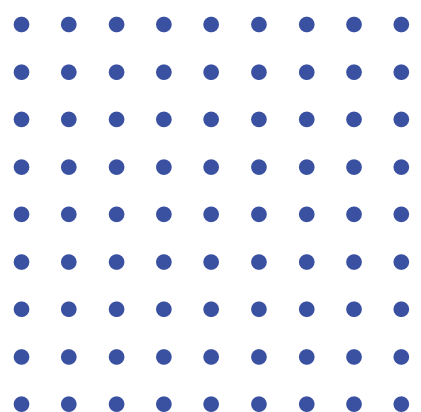

FIgURE 1: Descartes coordinate grid map.

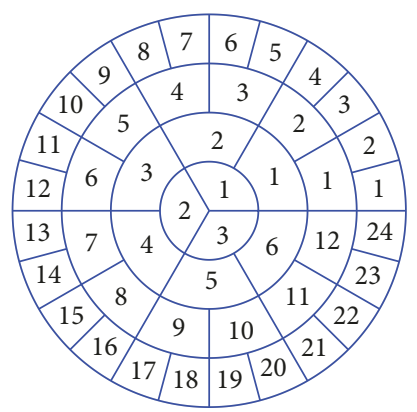

Figure 2: Polar coordinate grid map.

the floor surface distribution is stochastic. The particularity of the walking constraint and the pose adjustment cost of the underground roadheader are not reflected in the above-mentioned methods. Therefore, most of these dynamic stochastic unstructured environment modeling problems can be more generally classified as a stochastic constraint network.

Based on the above, this study investigates the stochastic network unstructured spatial environment modeling and availability problem and increases the high-dimensional constraint vector and traffic cost in the constraint grid network (C-GNet) nodes and arcs based on grid two-dimensional (2D) terrain data and three-dimensional (3D) altitude data. A network topology with the walking cost weights is constructed considering the space and the walking constraints of the roadheader. The minimum cost of the network nodes and arcs was determined as the objective function to propose the variation self-adapting particle swarm optimization algorithm and optimize the region path.

\section{Materials and Methods}

2.1. Environment Model. The classical grid network partition environment model mainly includes a Descartes coordinate grid model (Figure 1) and a polar coordinate grid model (Figure 2), which represents the two-dimensional position information.

Net $=(P, K ; F)$ is a conventional grid network; $P$ is a set of nodes representing the grid position point $\left(x_{i}, y_{i}\right) ; K$ is the set of altitudes representing the altitude value of the grid

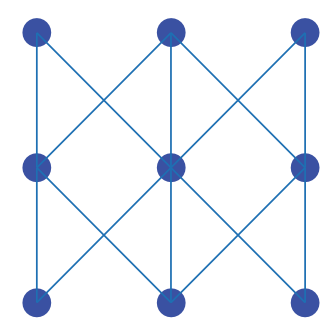

Figure 3: C-GNet diagram structure.

position point; and $F$ is the set of arcs representing the node connection path.

The classical grid network 2D terrain data and the 3D altitude data cannot reflect other dimensional data, such as traffic cost and geological influence cost, in the modeling of some stochastic dynamic network environment models without considering the numerical representation of random distribution and the behavior constraints of the roadheader. Therefore, performing research on the multidimensional constraint grid network and traffic cost information is of practical significance.

Definition 1. The 6-tuple $\sum=(P, K ; F, W, X, M)$ is a grid network system, which is the constraint grid network (CGNet) according to the following structural rules:

(1) Net $=(P, K ; F)$ is a conventional grid network.

(2) $K: P \rightarrow z_{i}=f\left(x_{i}, y_{i}\right)$ is the altitude function of C-GNet.

(3) $W: F \rightarrow\left\{w_{i}=f\left(x_{i}, y_{i}, z_{i}, t_{g}\right)\right\}$ is the weight function of C-GNet.

(4) $X: F \rightarrow\left\{X_{i}, i=1,2,3,4\right\}$ is the constraint variant set of C-GNet.

(5) $M: P \rightarrow \mathrm{Z}$ (set of nonnegative integer) is the token or state.

The surface traffic attribute information of the constrained grid node was established (Figure 3 ). The properties of the C-GNet structure parameters were defined as Property 2.

Property 2. $\Sigma=(P, K ; F, W, X, M)$, which satisfies the following conditions.

(1) $p \in P$ is any node of C-GNet if $\exists p_{1}, p_{2}, \ldots p_{N}$, making $\forall 1 \leq i \leq N,{ }^{\Delta} p_{i}=\left\{p \mid\left(x_{i-1}, y_{i-1}\right) U\left(x_{i}, y_{i-1}\right) U\left(x_{i+1}\right.\right.$, $\left.\left.y_{i-1}\right) U\left(x_{i-1}, y_{i+2}\right) U\left(x_{i}, y_{i+2}\right) U\left(x_{i+1}, y_{i+2}\right) \subset P\right\}$, and ${ }^{\Delta} p=p^{\Delta}$, ${ }^{\Delta} p$, and $p^{\Delta}$ are the preset and postset of $p$.

(2) $f \in F, f_{i, i+1}=f\left(p_{i, i} \rightarrow p_{i, i+1}\right)$, represents the directed arc between $\left(x_{i}, y_{i}\right)$ and $\left(x_{i}, y_{i+1}\right)$. The arc orientation depends on the starting position of the node. $\omega$ represents the arc length weight of C-GNet. $\theta$ represents the arc angle constraint. The state transition (position transfer) between the adjacent nodes is called transition: $\psi_{i-j}: M\left(p_{i}\right) \rightarrow M\left(p_{j}\right)$.

(3) In the C-GNet, the path from the source node $s$ to the target node $d$ cannot be closed, $\overrightarrow{\text { road }}: p_{s}, \psi_{s-a}, p_{a}, \psi_{a-b}$, $\ldots p_{d} \cdot \overrightarrow{\operatorname{road}}_{1}(s, d), \overrightarrow{\operatorname{road}}_{2}(s, d), \ldots . \overrightarrow{\operatorname{road}}_{n}(s, d)$ represent the 
road from the source nodes to the target nodes. $R(s, d)$ represents the set of paths, and the total cost expression for a path is $W_{r}(s, d)=\sum_{i=s}^{d} w_{i}=\sum_{i=s}^{d} f_{\text {travel-condition }}^{i}$. The mathematical expression of the optimal path $R(s, d)$ is transformed into solving the minimum cost path in the path set.

$$
\begin{aligned}
W_{\min }(s, d) & =\min \left(\sum_{i=s, j}^{d} w_{i} \psi_{i-j}\right) \\
& =\min \left(\sum_{i=s, j}^{d} f_{\text {travel-condition }}^{i} \psi_{i-j}\right) \\
\sum_{i=s, j}^{d} \psi_{i-j} & \leq\left|P_{r}^{\text {num }}\right|-1 \\
2 & \leq\left|P_{r}^{\text {num }}\right| \leq m+1 \\
P_{r}^{\text {num }} & \subset\{2,3,4 \ldots m+1\} \\
\psi_{i-j} & = \begin{cases}0, & \underset{\operatorname{road}}{\longrightarrow}(i, j) \notin R(s, d) \\
1, & \underset{\operatorname{road}}{\longrightarrow}(i, j) \in R(s, d) .\end{cases}
\end{aligned}
$$

In the traffic cost model, $W_{\min }(s, d)$ is the objective function value. Equations (2) to (5) denote the constraint function. The transition $\psi_{i-j}$ indicates whether the destination path has $\operatorname{arcs} f^{i-j}=f\left(p^{i} \rightarrow p^{j}\right) . P_{r}^{n u m}$ is the subset of all nodes in the target path. $\left|P_{r}^{\text {num }}\right|$ is the number of all nodes in the set. $\psi_{i-j}=0$ indicates that the node transition does not belong to the target path. $\psi_{i-j}=1$ indicates the opposite situation.

The traffic cost of the path network model is established, the nodes and the arcs of which have stochastic attributes determined as Definition 3.

Definition 3. The network stochastic characteristics are mainly embodied in the weight function $W$ of the C-GNet arc: $F \rightarrow\left\{\begin{array}{c}f_{\text {travel-condition }}^{i}=f\left(x_{i}, y_{i}, z_{i}, t_{g}\right), \\ i=1, \ldots N ; g=1,2,3\end{array}\right\}$. When the arc weight function of the network node dynamic randomly changes, $W(i)$, which is the arc weight function, becomes a stochastic process. Equation (6) denotes the dynamic stochastic constraint grid net (C-GNet).

$$
\sum^{*}=(P, K ; F, W(i), X, M) .
$$

The cost function $\{W(i), i \in I\}$ in the dynamic stochastic C-GNet obeys the discrete stochastic process distribution. $I$ is the discrete sequence number, and $W(i)$ represents the discrete distribution. In an instance of a specific network node sequence number $I, W(i)$ is a discrete stochastic variable, whose corresponding probability is expressed as $p(i)=$ $p\left(\psi_{i-j}\right)$ and $\sum_{i} p(i)=\sum_{i=i-1, j=j-1}^{i+1, j+1} p\left(\psi_{i-j}\right)=1$.

2.2. Guidance Factor and Network Cost Model of C-GNet. The C-GNet model has the path guidance characteristics. Path planning mainly combines the geological and guidance factors of the special environment. The guidance factor formula is defined as follows:

$$
g(i)=|d(i)| \times a
$$

where $i$ represents the order number of the path points to be selected, $i=2,3 \ldots 9 ; d$ is the distance between the central line of each path point; and $a$ is the guide coefficient and span belonging to $[0,1]$. Its size reflects the influence of the path point deviation from the degree of center to the overall path.

We propose herein the concept of centripetal degree based on each path point corresponding to a guidance factor $g$ (see (8)). Consider

$$
G=\sum_{i=1}^{N} g(i)
$$

The information contained in the arc is $(\operatorname{Inf}, \theta r, \theta p, \theta t, L)$, where Inf indicates the geological cost; $\theta r$ indicates the rolling angle of the arc ground surface; $\theta p$ indicates the angle of pitch; $\theta t$ indicates the steering angle; and $L$ is the arc length.

$$
W_{r}=\sum_{i=1}^{N-1}\left(I n f_{i}+\theta r_{i}+\theta p_{i}+\theta t_{i}+L_{i}\right)
$$

In (9), $i=1,2,3, \ldots, N-1$, where $N$ represents the number of nodes for path planning. The total cost formula of the path is denoted in

$$
W_{r}(s, d)=W+G
$$

Therefore, the optimal path planning aims to find the comprehensive cost of $\min \left(W_{r}(s, d)\right)$.

2.3. Variation Self-Adapting Particle Swarm Optimization (VSAPSO). This study compared and verified four kinds of PSO algorithms, including this method, to verify the VSAPSO algorithm performance. The simulation experiments of this method were completed under MATLAB R2016a. The operation system was Windows 10 64-bit operation system, while the CPU was i5-4590.

2.3.1. Algorithm Principle. The classical particle swarm optimization algorithm [22] is expressed as

$$
\begin{aligned}
v_{i d}(t+1)= & w \times v_{i d}(t)+c_{1} \times r_{1} \times\left(p_{i d}-x_{i d}(t)\right)+c_{2} \\
& \times r_{2} \times\left(p_{g d}-x_{i d}(t)\right) \\
x_{i d}(t+1)= & x_{i d}(t)+v_{i d}(t+1) \\
v_{i d}= & \begin{cases}v_{\max } & v_{i d}>v_{\max } \\
-v_{\max } & v_{i d}<-v_{\max } \\
v_{i d} & \left|v_{i d}\right|<v_{\max }\end{cases} \\
w(t)= & w_{\max }-\frac{w_{\max }-w_{\min }}{T_{\max }} t
\end{aligned}
$$


where $v_{i d}$ is the speed of the current particle $i ; x_{i d}$ is the position of the current particle $i ; c_{1}$ and $c_{2}$ are the learning factors; $r_{1}$ and $r_{2}$ are random numbers among $[0,1] ; p_{i d}$ is the personal best position of the current particle $i ; p_{g d}$ is the global best position of the current particle $i ; v_{\max }$ is the maximum speed; $w_{\max }$ is the maximum inertia weight; $w_{\min }$ is the minimum inertia weight; $t$ is the number of iterations; and $T_{\max }$ is the maximum number of iterations.

This method has the advantages of a simple principle, a few controlled parameters, and a fast convergence speed. However, it also has the disadvantage of easy convergence to local optimal and low search precision. Therefore, the VSAPSO algorithm was proposed in this study:

$$
w=w_{\max }-\frac{\left(w_{\max }-w_{\min }\right) \times\left(f_{\max }-\text { fitness }(\mathrm{i})\right)}{f_{\max }-f_{\min }}
$$

where fitness $(i)$ indicates the fitness for each generation of $i$ particles; $f_{\max }$ indicates the maximum fitness; and $f_{\min }$ indicates the minimum fitness.

This proposed algorithm can automatically adjust the parameters of the inertia weight $w$ according to the current particle fitness. The $w$ value increases when the fitness value is large, thereby improving the search speed and the global search ability of particles. The $w$ value becomes smaller when the fitness value is small, thereby reducing the particle search speed and improving the local search ability of particles.

The modified inertia weight $w$ has a larger adjustment range, which improves the search capability of the algorithm. We used herein the way of mutation in the genetic algorithm to enable the particles to randomly reset positions at a certain probability, such that they can jump out of the original location to research, thereby reducing the probability of particle swarm falling into local minimum. The way of mutation is shown in (16) as follows:

$$
x_{i d}= \begin{cases}x_{\max } \times \operatorname{rands}(1, D) & \operatorname{rand}() \geq p \\ x_{i d} & \operatorname{rand}()<p\end{cases}
$$

where $p$ represents a mutation threshold; $x_{\max }$ represents the maximum value allowed by the location; and rands $(1, \mathrm{D})$ represents a $\mathrm{D}$ random number between 0 and 1 .

2.3.2. VSAPSO Performance Test. We used herein four kinds of test functions to test the standard PSO algorithm, adaptive PSO algorithm with modified inertia weight formula (APSO), adaptive weight particle swarm optimization algorithm with the compression factor (CFWPSO), and VSAPSO.

The four kinds of PSO algorithms have the same basic parameters, particle swarm size $N=40$, maximum speed $V_{\max }=1$, maximum inertia weight $w_{\max }=0.9$, minimum inertia weight $w_{\min }=0.4$, and learning factor $c 1=c 2=2.05$, where the VSAPSO mutation threshold is $p=0.98$. The end condition of the four kinds of algorithms is to reach the maximum iteration step of 100 steps, and the four kinds of test functions are all four-dimensional functions.

When the maximum number of iterations is achieved, the algorithm runs 10 times to obtain the fitness decreasing

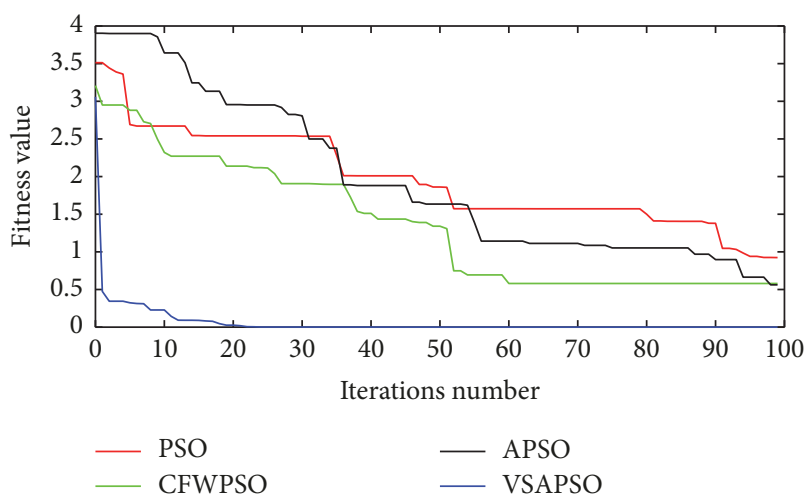

Figure 4: Fitness curve decreasing under the Griewank function.

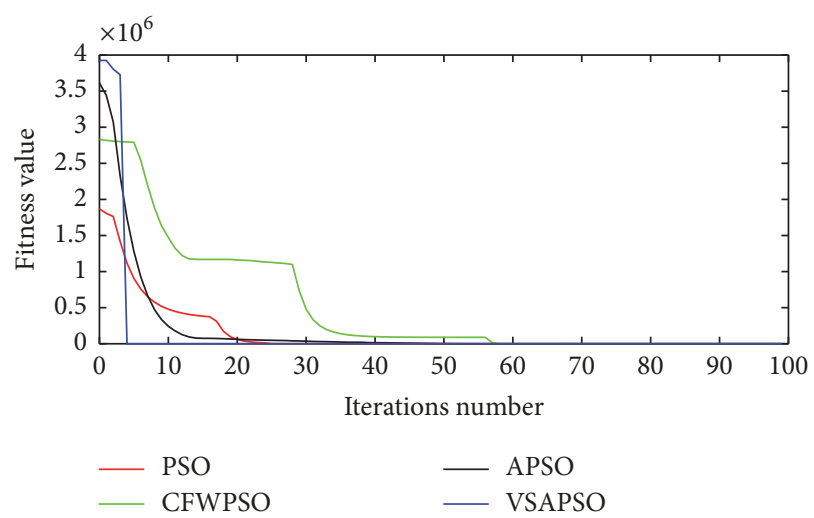

FIGURE 5: Fitness curve decreasing under the Rosenbrock function.

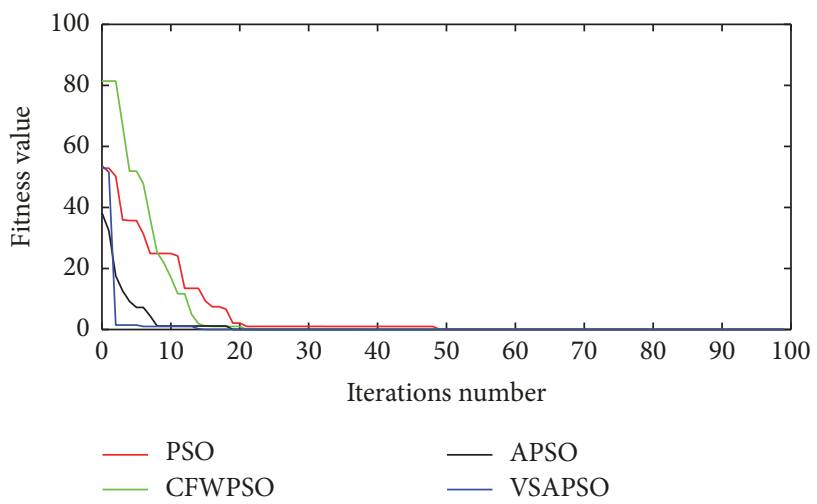

Figure 6: Fitness curve decreasing under the Rastrigin function.

curve of each algorithm when it reaches the minimum fitness function value under each test function (Figures 4-7).

The initial values of the algorithms were randomly assigned; hence, the starting points of the curves were different. As shown in Figures 4-7, the PSO and APSO algorithms illustrate that the curve does not decrease in the number of iterative steps when in convergence. The effect of the CFWPSO algorithm was consistent with the two above-mentioned items. Under the Ackley function shown in Figure 7, the fitness value of the PSO/APSO and CFWPSO algorithms even occurred over 20 in 100 steps 


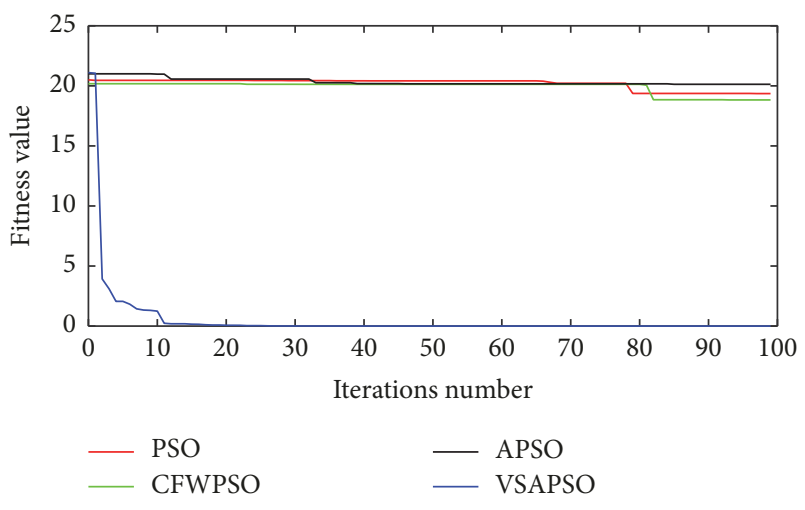

Figure 7: Fitness curve decreasing under the Ackley function.

TABle 1: Minimum fitness.

\begin{tabular}{lcccc}
\hline Test function & PSO & APSO & CFWPSO & VSAPSO \\
\hline Griewank & 0.327 & 0.7778 & 0.3195 & $2.220 \mathrm{e}-15$ \\
\hline Rosenbrock & 0.031 & $6.697 \mathrm{e}-4$ & 0.0011 & $7.459 \mathrm{e}-18$ \\
\hline Rastrigin & $3.55 \mathrm{e}-15$ & $6.28 \mathrm{e}-7$ & $1.88 \mathrm{e}-10$ & 0 \\
\hline Ackley & 19.777 & 16.717 & 19.837 & $7.808 \mathrm{e}-7$ \\
\hline
\end{tabular}

TABle 2: Variance.

\begin{tabular}{lcccc}
\hline Test function & PSO & APSO & CFWPSO & VSAPSO \\
\hline Griewank & 0.552 & 0.146 & 0.2653 & $1.261 \mathrm{e}-22$ \\
\hline Rosenbrock & 157.8 & 58.3 & 70.813 & $5.825 \mathrm{e}-27$ \\
\hline Rastrigin & $2.605 \mathrm{e}-21$ & $2.453 \mathrm{e}-9$ & $5.5779 \mathrm{e}-13$ & 0 \\
\hline Ackley & 1.319 & 0.037 & 0.0186 & $2.876 \mathrm{e}-9$ \\
\hline
\end{tabular}

because of the lack of global search ability and local minima when these three algorithms were convergent, leading to the inability to converge to the minimum. To sum up, under the four functions, the VSAPSO algorithm had a stronger global search ability and was better than the PSO/APSO and CFWPSO algorithms in the decline speed.

The fitness function is the optimization objective function of the PSO algorithm. In this paper, the comprehensive cost function of path planning is our fitness function. To minimize the energy and time consumption of the roadheader, the minimum value of the comprehensive cost function is set as the optimization target of the PSO algorithm. The PSO algorithm itself has the randomness of optimization. Therefore there will be a certain fluctuation in the optimization results of the algorithm. It is necessary to evaluate the advantages and disadvantages of the algorithm through the mathematical statistics. When the maximum number of iterations is achieved, the algorithm runs 10 times to obtain the minimum fitness function value, variance, and mean of each algorithm under each test function (Tables 1-3).

The inertia weight adjustment strategy proposed in this paper can adjust the search speed of particles according to the position of particles. And the convergence of the algorithm also can be increased. The minimum fitness value of the algorithm can be used to evaluate the limit optimization ability of the algorithm.
TABLE 3: Average value.

\begin{tabular}{lcccc}
\hline Test function & PSO & APSO & CFWPSO & VSAPSO \\
\hline Griewank & 1.232 & 1.007 & 1.0371 & $6.621 \mathrm{e}-12$ \\
\hline Rosenbrock & 14.695 & 6.438 & 16.7508 & $4.980 \mathrm{e}-14$ \\
\hline Rastrigin & $1.676 \mathrm{e}-11$ & $4.489 \mathrm{e}-05$ & $3.3992 \mathrm{e}-07$ & 0 \\
\hline Ackley & 20.159 & 19.627 & 20.1086 & $2.862 \mathrm{e}-5$ \\
\hline
\end{tabular}

Table 1 showed that the minimum fitness function value of the VSAPSO algorithm proposed in this study was the highest compared with that of the PSO/APSO and CFWPSO algorithms. The convergence accuracy was the highest.

Variance of minimum fitness represents the fluctuation of minimum fitness function value obtained by algorithm optimization. The probability that different improved PSO algorithm can stabilize a certain value is also different. The smaller the fluctuation, the better the stability of the algorithm.

Average of minimum fitness represents the optimization ability of the algorithm in the usual case and represents the noncontingency of the minimum value that the algorithm can reach. If the minimum value of the algorithm can be achieved many times, it shows that the algorithm can reach smaller fitness value by chance. This noncontingency is more appropriate in the use of mean value in the mathematics.

In Tables 2 and 3, it was presented that the average value and the variance of the VSAPSO algorithm were smaller than those in the PSO/APSO and CFWPSO algorithms and indicated that the stability and the convergence of VSAPSO were the highest. The inertia weight adjustment strategy and the compilation strategy proposed in this paper made the VSAPSO algorithm more stable to find the minimum fitness value. If the minimum fitness value generally deviated from the mean value, the stability and reliability of the algorithm were not high. On the contrary, it showed that the algorithm has high stability and credibility. Consequently, the proposed VSAPSO algorithm had a faster speed and a higher precision in convergence than the other three algorithms.

\section{Results and Discussion}

3.1. Environment Modeling. Because of the special underground coal mine traveling environment in this paper, it belonged to the narrow space roadway terrain structure. There were the strong coal dust, humid air, weak light, and the threat of gas to human and the electrical and electronic equipment in coal mine. These posed a great obstacle to path planning of roadheader, and it was difficult to carry out field test in the coal mine before the verified theory method. Therefore, the authors and their team had carried out related test research on the position and orientation detection method of roadheader in the ground environment, such as laser automatic measurement method.

The simulation coal mine roadway used in this paper was based on the size and driving data of EBZ type roadheader. It was a special lightweight roadheader, which was suitable for coal roadway, half coal rock roadway and soft rock roadway, 


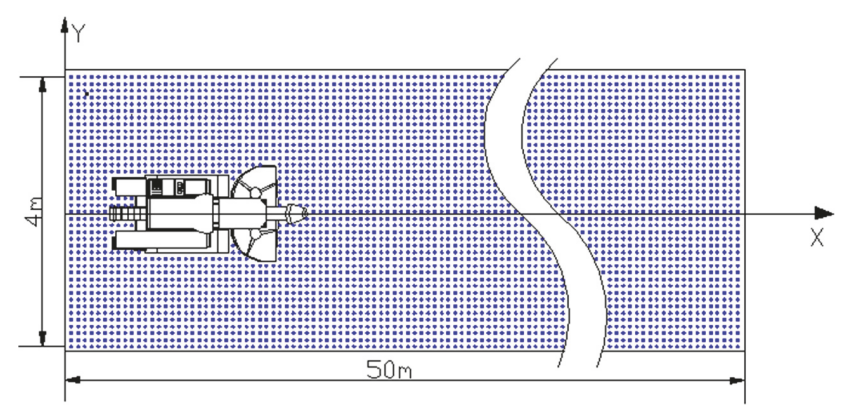

Figure 8: Simulation model of roadway.

and tunnel heading. The maximum cutting height was $2.8 \mathrm{~m}$, and the maximum cutting bottom width was $3.52 \mathrm{~m}$. The effective section area is $9.8 \mathrm{~m}^{2}$, and wider cutting width was less than 16 degrees.

By using the laser automatic measurement method, the position information of the roadheader in the tunnel was measured to determine the coordinate value in the map, and the position and posture information was measured. The roll angle, the pitch angle, and the steering angle of the roadheader were obtained by the solution, which provided the actual value of the cost function value solution of the method proposed in this paper. The test basis and the steps of the measurement were

(a) Model the laneway and deploy total station measuring platform, rear view prism, and prism to be measured.

(b) Level and adjust the total station, the tested prism, and the rear viewing prism.

(c) Use the total station to collect the position and orientation data of the roadheader.

(d) Calculate the position and orientation data of the roadheader in order to obtain the roll angle, pitch angle, steering angle, and location information of the roadheader.

The experimental environment and real view of experimental scenario were shown in Figures 9 11.

The experimental data showed that the positioning accuracy of the $\mathrm{Y}$ axis was better than that of $10 \mathrm{~cm}$, and the positioning accuracy of $\mathrm{X}$ and $\mathrm{Z}$ axis was better than that of $2 \mathrm{~cm}$ under the distance of $1.2 \mathrm{~m}$ spacing and the distance of $17 \mathrm{~m}$ between the launching station and the roadheader.

Through the data acquisition process of the position and posture of the above roadheader, the information needed for the calculation of the cost function value in the C-G grid map could be obtained. The data obtained from the measured data could be brought into the roadheader cost function model proposed in this paper. Based on this test data, stochastic C$\mathrm{G}$ grid map proposed in this paper could be set up (Figure 8), and the VSAPSO algorithm was used to excavate the C-G grid map information to plan optimal path of roadheader.

The establishment steps of the stochastic C-GNet environment model are as follows.

(1) The single path forward distance of the roadheader is determined according to the step distance of the drifting machine $L_{i}=0.8 \mathrm{~m}$. The transverse distance is $4 \mathrm{~m}$.

(2) The node resolution of the constraint grid is determined according to the stepping control precision of the

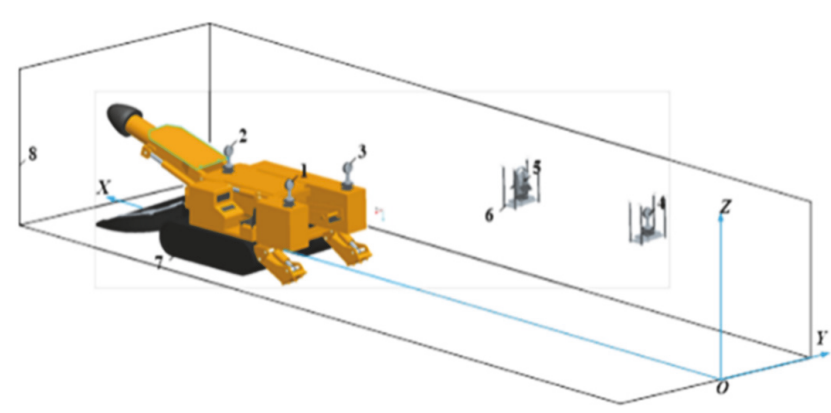

FIGURE 9: Laser automatic measurement.

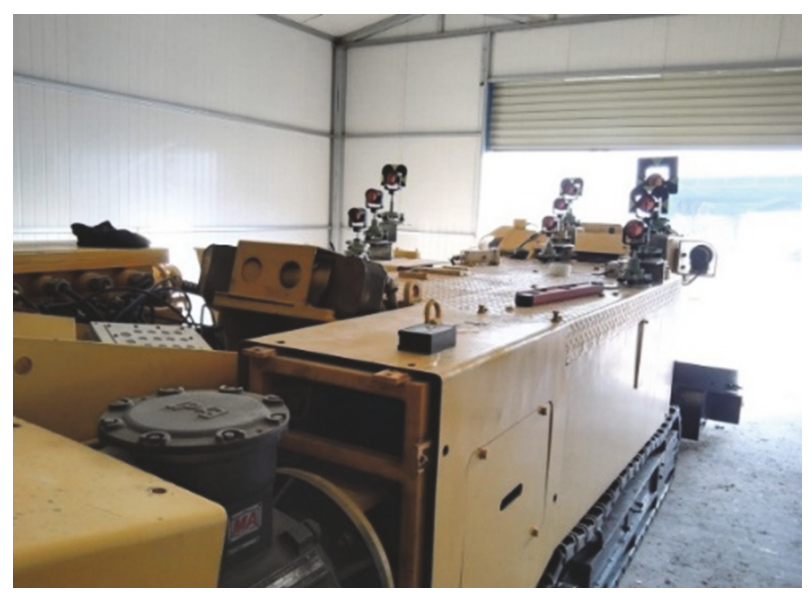

FIgure 10: Position measurement device.

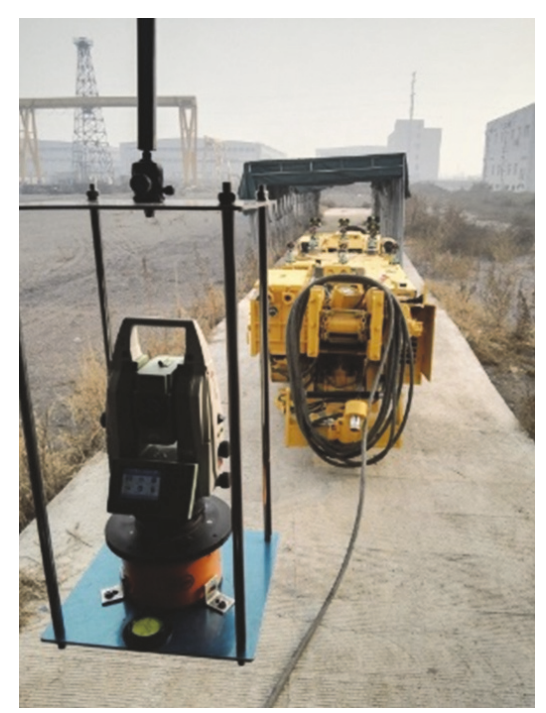

FIGURE 11: Real view of experimental scenario.

roadheader $0.1 \mathrm{~m}$. The parameter assignments of $n \in N$ and $N=9$ in $\overrightarrow{\operatorname{road}}_{n}(s, d)$ are determined.

(3) The geological cost $f_{\text {travel-condition }}^{i}=\left(\operatorname{Inf}_{i}+\theta r_{i}+\right.$ $\left.\theta p_{i}+\theta t_{i}\right) \psi_{i-j}, j=n \operatorname{ext}(i)$, is determined according to the sum of the total cost weights based on the node of the path: $W_{r}(s, d)=\sum_{i=s}^{d} w_{i}=\sum_{i=s}^{d} f_{\text {travel-condition }}^{i}$. 


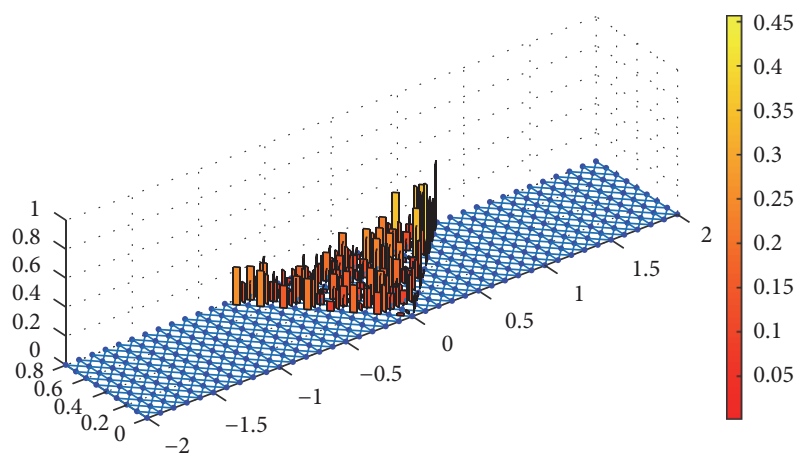

FIGURE 12: Cost simulation obeying the normal distribution.

(4) According to the behavior constraints of the roadheader in the narrow and long tunnel in Figure 9, formula $j=\operatorname{next}(i)$ indicates the postposition node that is the longitudinal direction of the current node, with $45^{\circ}, 90^{\circ}$, and $135^{\circ}$ as the three direction nodes.

(5) The precision position measurement system of the roadheader in the mine determines the $3 \mathrm{D}$ coordinates and completes the calculation of the pitch, roll, and deflection. The reliability of the method is verified by the simulation data based on the value of $f_{\text {travel-condition }}^{i}$.

(6) From the actual roadheader tunneling environment, the roadway is close to the middle line after tunneling. The coal-receiving condition here is relatively good, whereas that on both sides of the roadways is relatively poor. Therefore, the closer the roadway floor condition, the better the distance, and the worse the middle line condition. According to the distance between the nodes and the middle line, the cost value distribution of the arc path is assumed to be a normal distribution. The grid network model is set up as shown in Figure 12. We first calculate the standard normal distribution of the interval $[-2,2]$ and then take 41 intervals of 0.1 normal distribution values. Each arc is determined according to the content of Definition 3 (see (17)). Consider

$$
W(i)=f_{\text {travel-condition }}^{i}=\operatorname{rand}(1) \times \frac{(0.5-N(i))}{0.5}
$$

where $\operatorname{rand}(i)$ indicates the random number between 0 and 1 ; $N(i)$ represents the normal distribution value corresponding to the arc; and $i$ is the number of network nodes in $i=$ $1,2 \ldots, 41$.

(7) We set the centrality of cost $g(i)=\left|D_{i}\right| \times a_{g}$ according to the distance $D$ from the center of the roadheader path. $D$ is the distance of each path from the center line in centimeters, the value of which is for the dimensionless form of the distance. $a_{g}$ represents the guidance coefficient; $\left|a_{g}\right| \in[0,1]$. The centripetal degree concentration indicates the influence of the path point deviation from the center degree to the overall path. The greater the coefficient, the closer the path closer to the middle line. Herein, $a_{g}=0.5$, and the numerical value aims to satisfy the path point at a feasible interval and guide the path to travel along the center line.

(8) Integrating steps 6 and 7, we propose herein the traffic cost formula $W_{r}(s, d)=W+G=\sum W(i)+\sum g(i)$. Figure 10
TABLE 4: Comparison of path-planning results.

\begin{tabular}{lccc}
\hline Type & Minimum fitness & Mean & Variance \\
\hline PSO & 1.304 & 1.372 & 0.062 \\
CFWPSO & 1.154 & 1.284 & 0.009 \\
VSAPSO & 1.071 & 1.176 & 0.007 \\
\hline
\end{tabular}

shows the network traffic cost model with the horizontal direction for the 41 points and the longitudinal axis' nine steps of the roadheader. An example of random starting nodes $(0,0)$ was established as a grid map based on this (Figure 13)

There were three algorithms used to plan path of the roadheader. Each path planning algorithm runs 10 times, and the path of the minimum fitness is obtained as planned by the three algorithms shown in Figures 14 and 15.

Figures 14 and 15 show that the coincidence path of the $0 \sim 0.1$ part in the diagram was planned by PSO and CFWPSO, while $0.2 \sim 0.3$ part is determined by CFWPSO and VSAPSO. The coincidence path of the $0.4 \sim 0.5$ part in the diagram was planned by PSO and VSAPSO, while 0.5 0.8 part is determined by CFWPSO and PSO.

The minimum comprehensive cost function value, mean, and variance of the statistical algorithm after running 10 times were shown in Table 4.

It could be seen from Table 4 that, compared with the other two PSO algorithms, the minimum comprehensive cost function of the VSAPSO algorithm was minimized by comparing the minimum comprehensive cost function value under the premise of the stochastic starting point of the path planning. Thus, the VSAPSO algorithm had better optimization ability in the path planning problem. According to the comparison of variance, the result of path planning using the VSAPSO algorithm was smaller, which indicated that the path planning was more stable using the VSAPSO algorithm. Furthermore, the mean value of the path planning using the VSAPSO algorithm was smaller by comparing the mean value. It showed that the path planning was obtained by using the VSAPSO algorithm. The probability of smaller composite cost function value was higher and the result was more believable.

On the premise of stochastic path planning and stop point, the VSAPSO algorithm was more efficient in the three algorithms, and the results were more stable and more reliable.

3.2. Stochastic C-GNet Test under Multitarget Points. Taking the actual working conditions of the roadheader in the tunnel as an example, the cutting boundary can be compensated by the motion of the cutting arm; hence, the moving target point cannot be unique. In the simulation model, we define the set of stochastic C-GNet target nodes as $\operatorname{Dr}, \operatorname{Dr}(i) \in$ $[-0.3,0.3]$, and the source node $P_{s} \in S r$ as the random source node $(0.2,0)$. The VSAPSO algorithm was used to simulate the multitarget set random C-GNet test under the guidance factor.

Figure 16 shows that the path point $P_{d}$ was found under the above-mentioned conditions of the grid map, $P_{d} \notin A r$. 
TABLE 5: Minimum integrated cost value corresponding to each path.

\begin{tabular}{lccccccccccc}
\hline Target & $-0.5,0.8$ & $-0.4,0.8$ & $-0.3,0.8$ & $-0.2,0.8$ & $-0.1,0.8$ & $0,0.8$ & $0.1,0.8$ & $0.2,0.8$ & $0.3,0.8$ & $0.4,0.8$ & $0.5,0.8$ \\
\hline Total cost & 1.8 & 1.7 & 1.5 & 1.4 & 1.2 & 1.07 & 1.1 & 1.5 & 21.5 & 21.6 & 21.6 \\
\hline
\end{tabular}

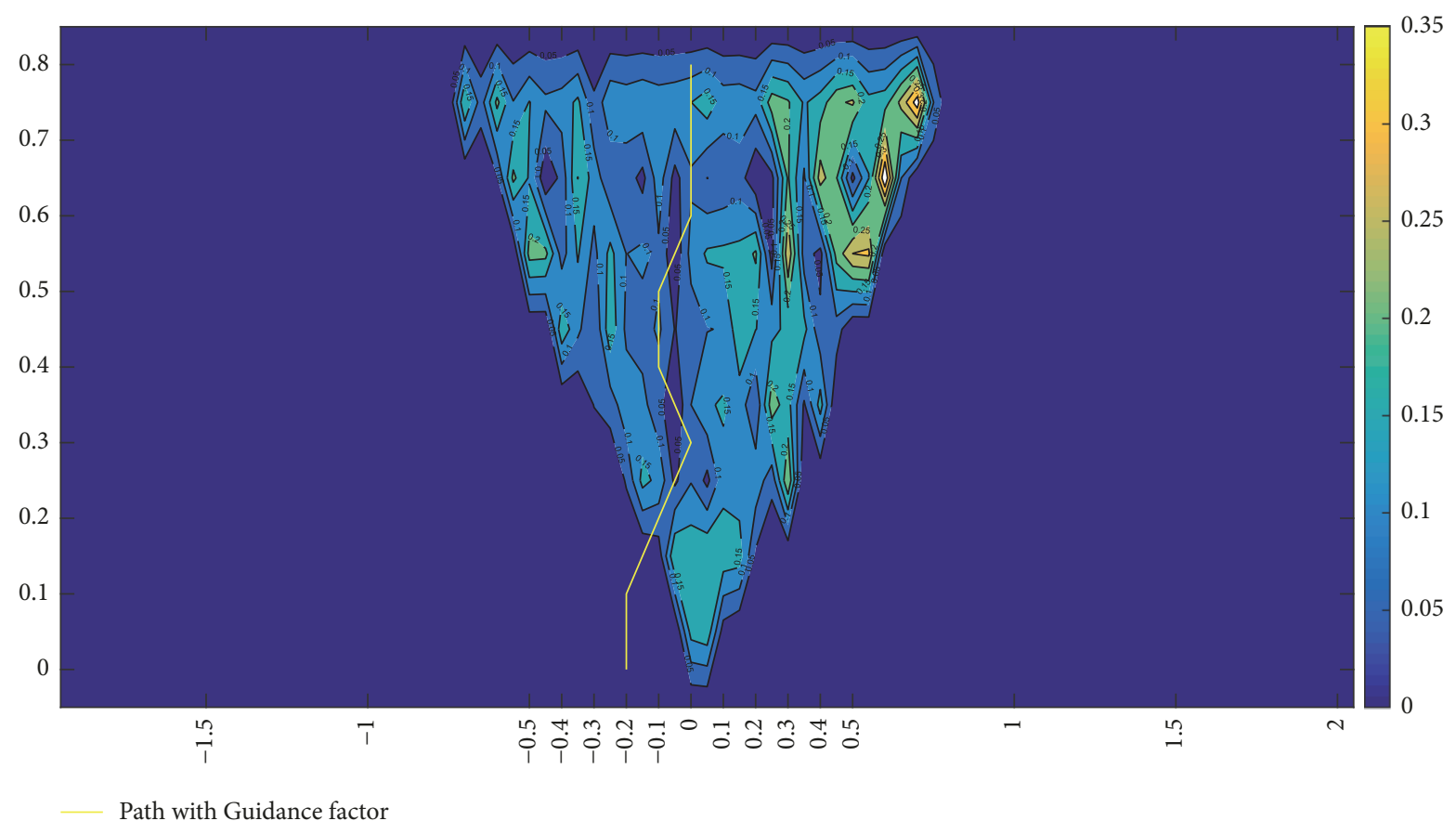

FIGURE 13: Stochastic C-GNet environment model.

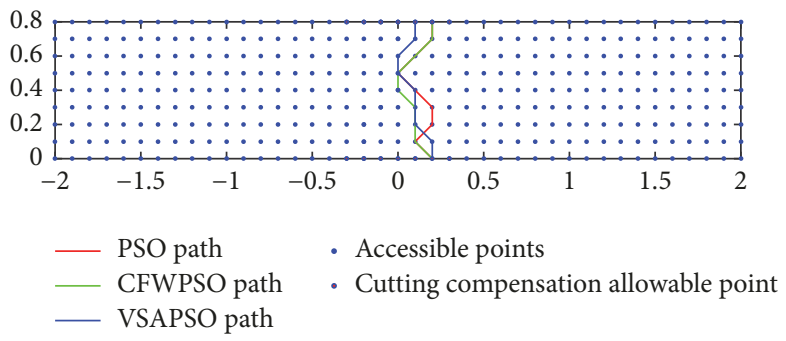

FIGURE 14: Path planning under simple C-Grid network.

Therefore, the guidance factor $G$ was added based on the arc consumption. Figure 17 presents the planning path when the guidance factor proportion was large. We can see from the figure that the guiding factor can implement the rectification work path well. However, if we consider that the guiding factor will cause a large roadheader traveling traffic cost, we must consider the compound factors of the guiding factor and the consumption values (Figure 18) after adjusting the guiding factor path planning algorithm.

The adjustment strategy was made according to the comprehensive influence factors of the geological traffic and the guidance factors in the above-mentioned terrain. An example of random starting nodes $(0.2,0)$ was established as a traffic cost model (Figure 19) and as a grid map based on this (Figure 20).
We performed path planning for all sets of target points using the VSAPSO algorithm (Figure 21).

Table 5 shows the cost $W(i)$ of the simulated network nodes obeying a normal distribution, target nodes $P_{d}=(0,0)$, minimum traffic cost $W_{r}(s, d)$, and best path (Figure 22).

After fully considering the stochastic characteristics of the floor and the surrounding rock surface of tunneling after roadheader cutting, the cost function of the simulation roadway and the simulation modeling of the roadheader's path planning were completed. In addition, the adaptability of the theoretical method was verified. Under this theoretical model, the practical measurement and path planning need to further improve the reliability of the topographic survey data and prior knowledge of geological conditions. 


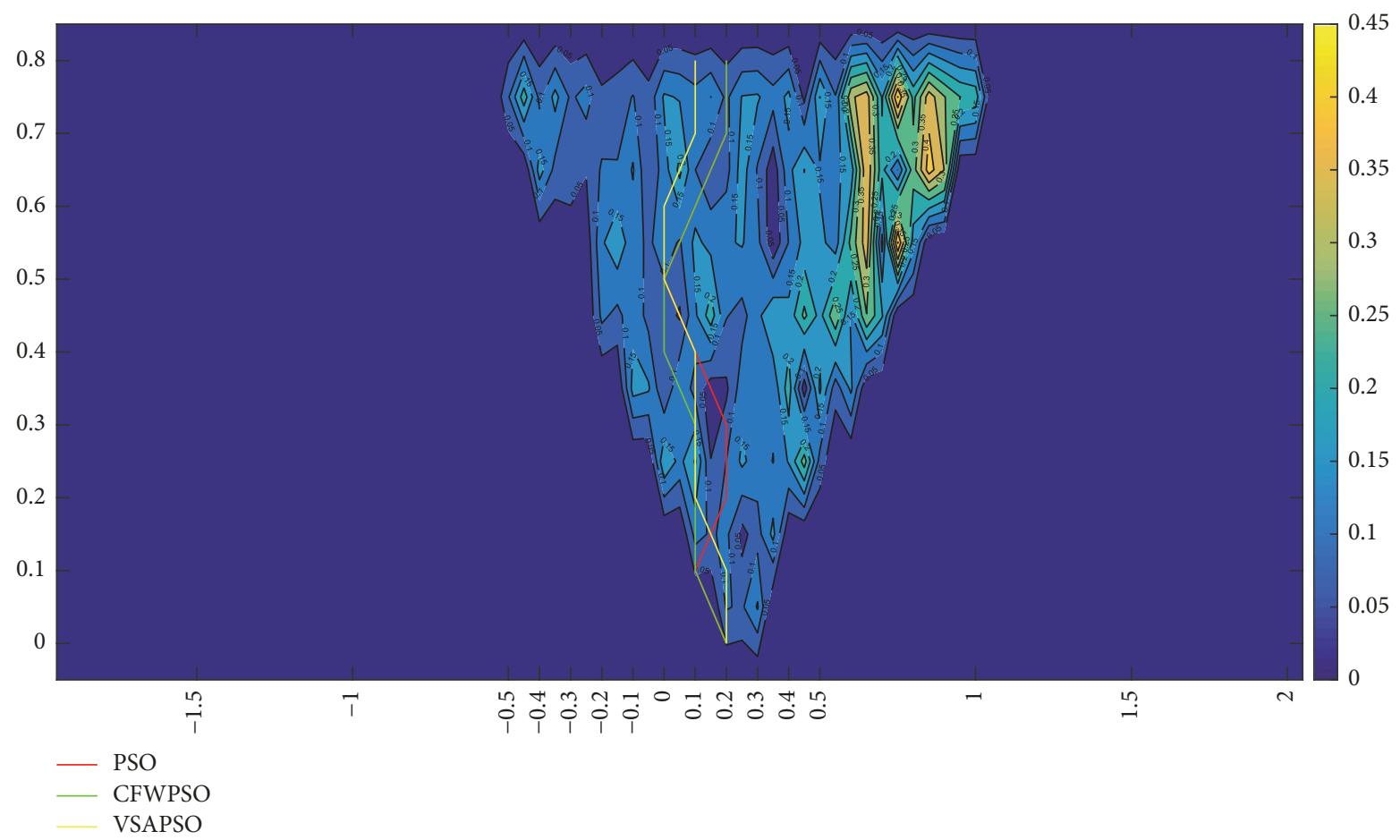

FIGURE 15: Comparison path planning under stochastic C-GNet environment model.

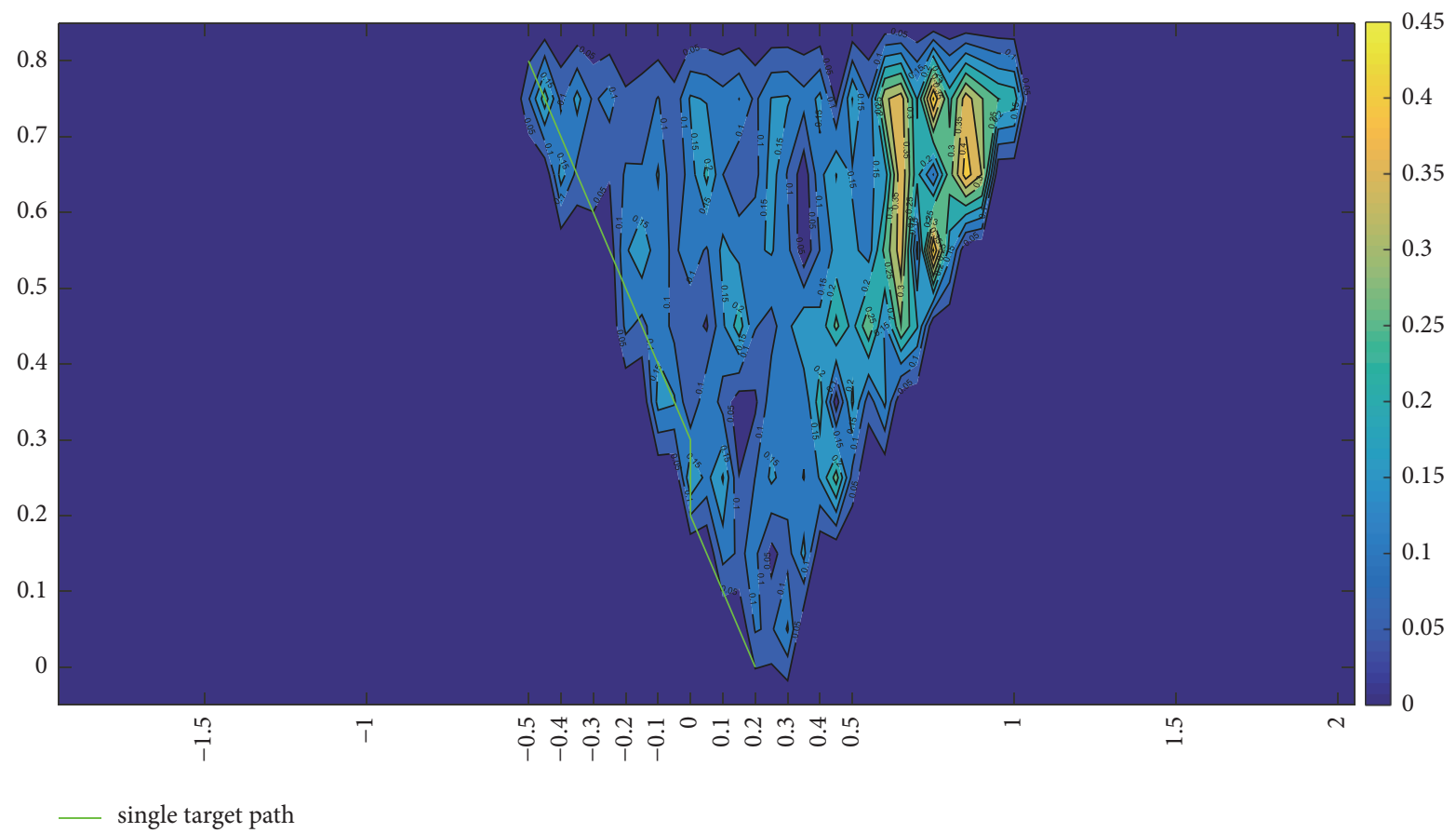

FIGURE 16: Single target path.

\section{Conclusions}

This work studied the stochastic network optimal path planning problem and analyzed the network structure characteristics, stochastic nature, and cost model of network arcs and nodes. We proposed a simulation for the stochastic process by analyzing the embodiment of the behavioral constraints in the network model. We took the 2D grid expansion for the high-dimensional grid computing cost model and comprehensive cost value into a $3 \mathrm{D}$ grid lower dimensional 


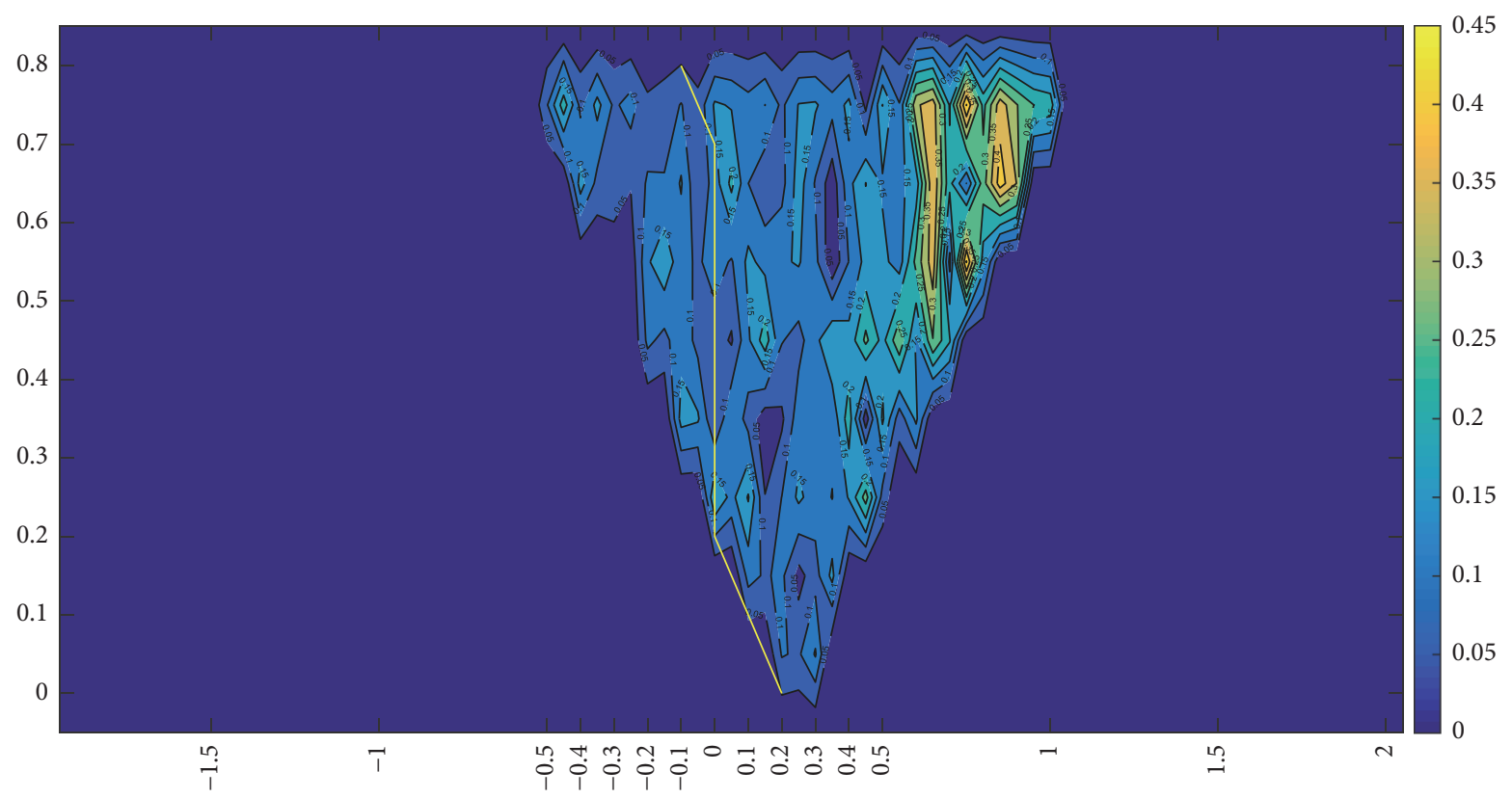

__ Path with Guidance factor

FIgURE 17: Path with the guidance factor.

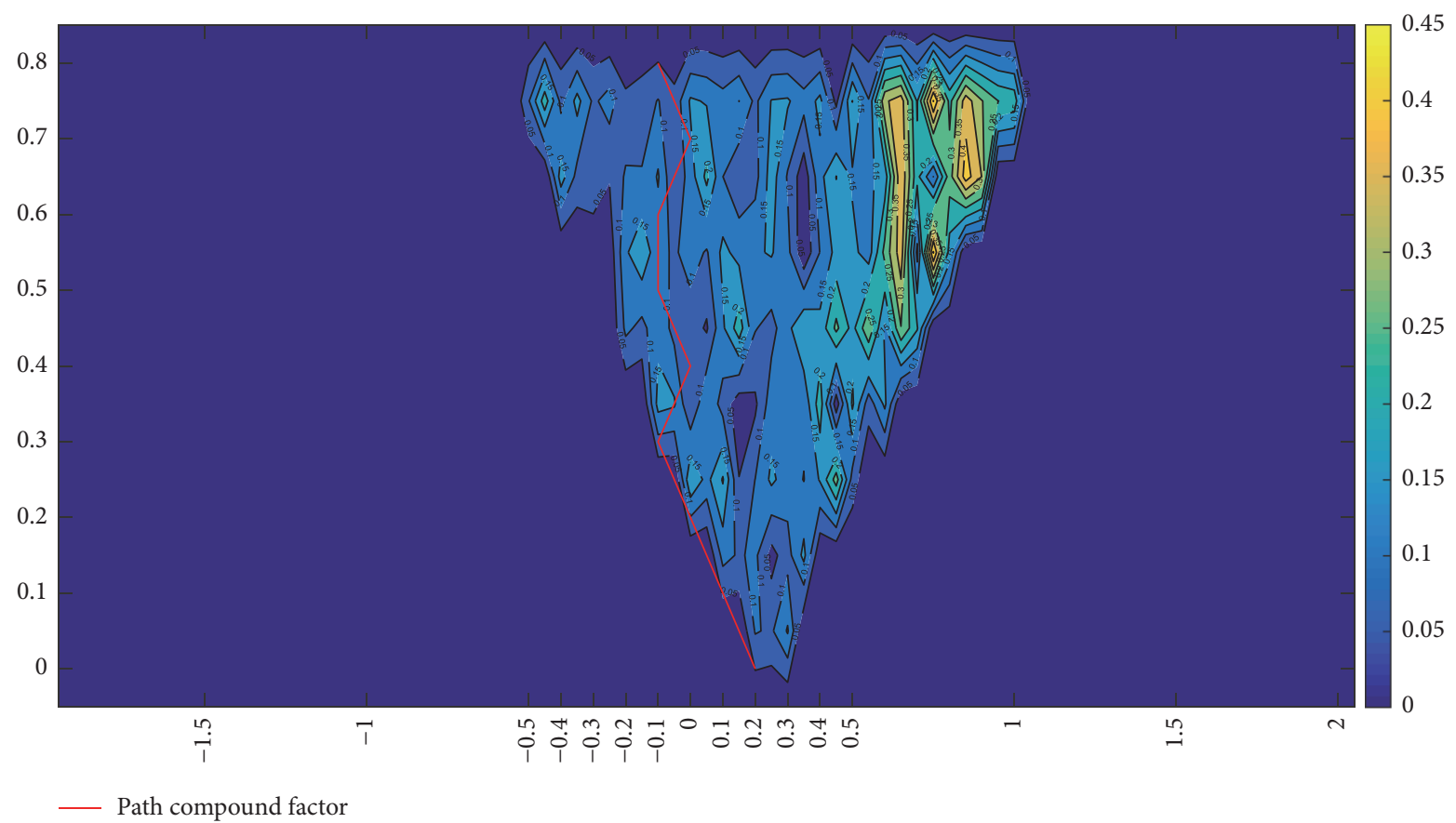

FIGURE 18: Path with the compound factor.

map using the VSAPSO optimization path planning method to solve the multiconstrained optimal path problem in an unstructured environment with stochastic C-GNet models. This study draws the following conclusions.

(1) The traditional environment modeling for the deterministic space structure is effective. However, a complete description of the cost price stochastic characteristics of the nodes and arcs cannot be observed in some network structures under the roadway space terrain composed of roadheader cutting molding and cutting quality influence. Hence, we proposed a stochastic C-GNet combined with the stochastic network characteristics of the terrain geological 


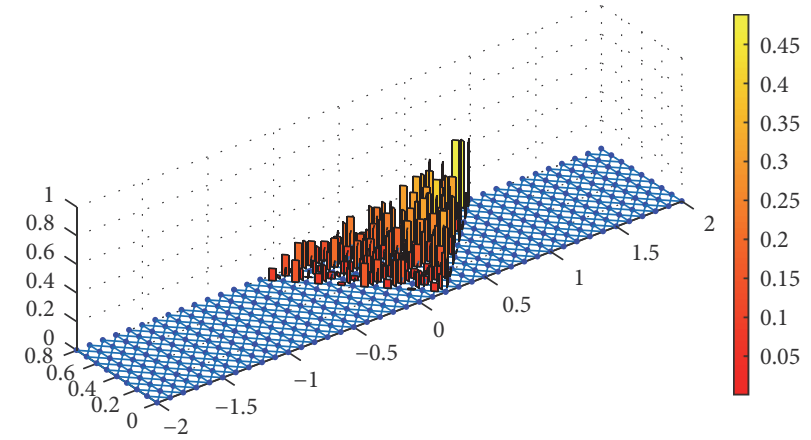

FIGURE 19: Cost of the random starting point $(0.2,0)$.

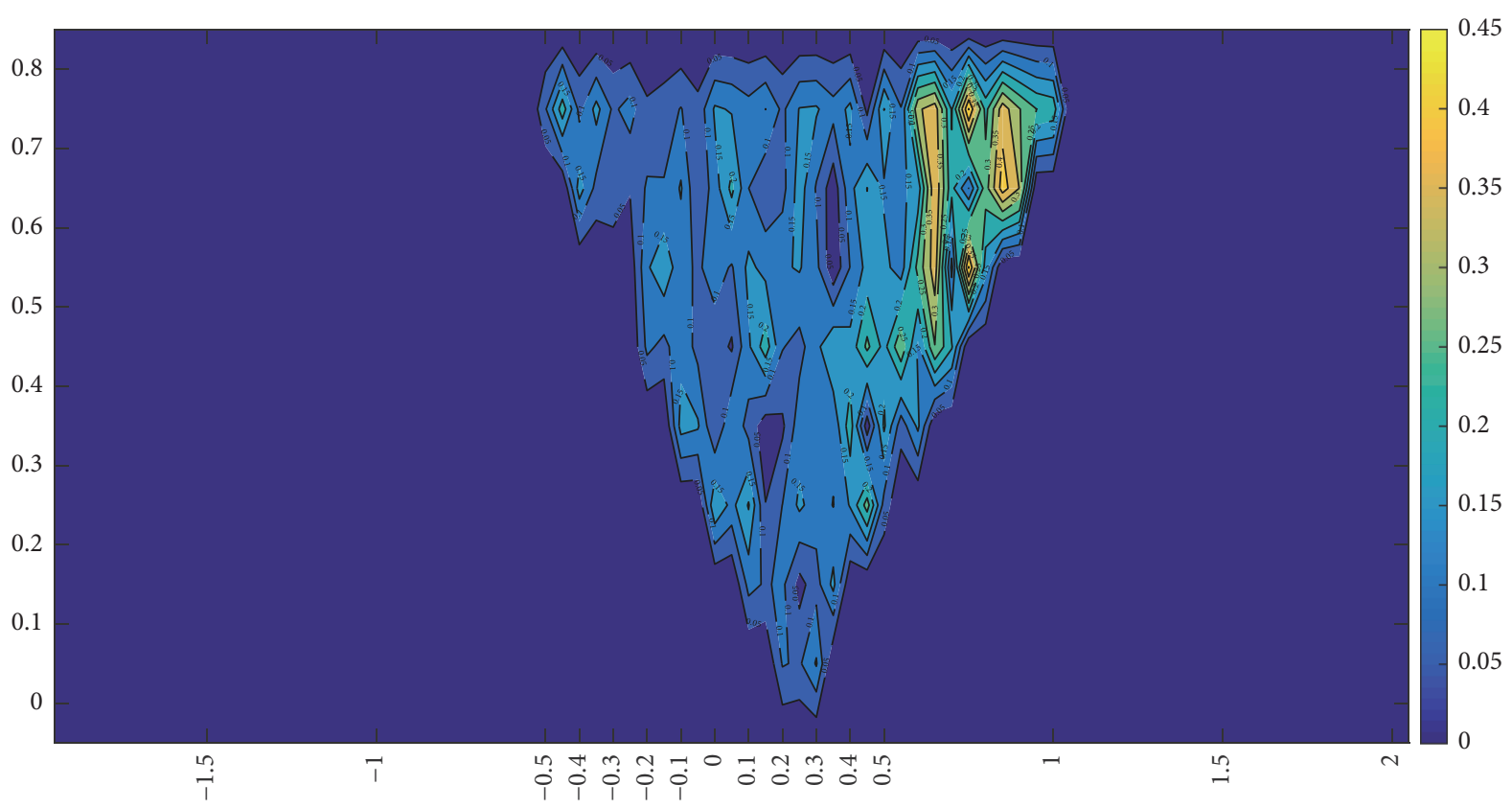

FIGURE 20: Stochastic C-GNet environment model of the random starting point $(0.2,0)$.

attributes under a narrow and closed nonstructural tunneling.

(2) The narrow and closed space belonged to the indoor local space category. The computational complexity was not high and using the particle swarm optimization algorithm verification environment model was feasible. The VSAPSO algorithm used in path planning and optimized in the convergence speed and accuracy met the target planning requirements, and the validation of which in the road in path planning was effective and practical.

(3) The stochastic constrained modeling method was based on the grid network environment, and the roadheader path planning was completed under a tunnel special environment. This modeling and optimizing method was suitable for the narrow priority large mechanical tunneling working space, but not limited to such problems, and solved the problem of intelligent transportation and special robot autonomous navigation in unstructured environment dynamic stochastic network optimization problems.

\section{Data Availability}

The data used to support the findings of this study can be provided by the corresponding author: yangjiannedved@ 163.com.

\section{Conflicts of Interest}

There are no conflicts of interest.

\section{Acknowledgments}

This work was supported by the National Basic Research Program of China (Grant no. 2014CB046306) and the Fundamental Research Funds for the Central Universities of Ministry of Education of China (Grant no. 800015FC). 


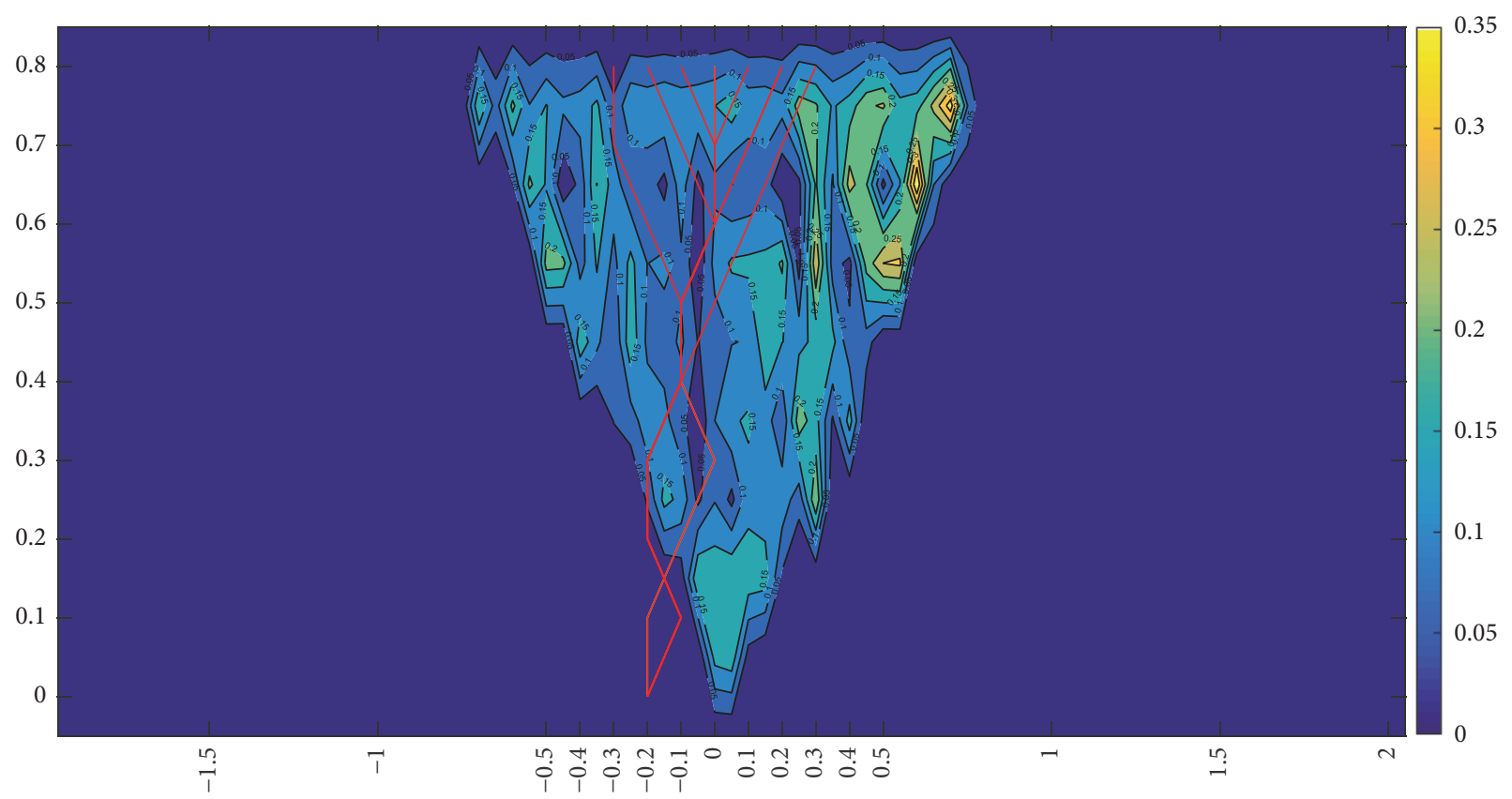

_ All planning paths for multiple targets

FIGURE 21: All planning path for multi target.

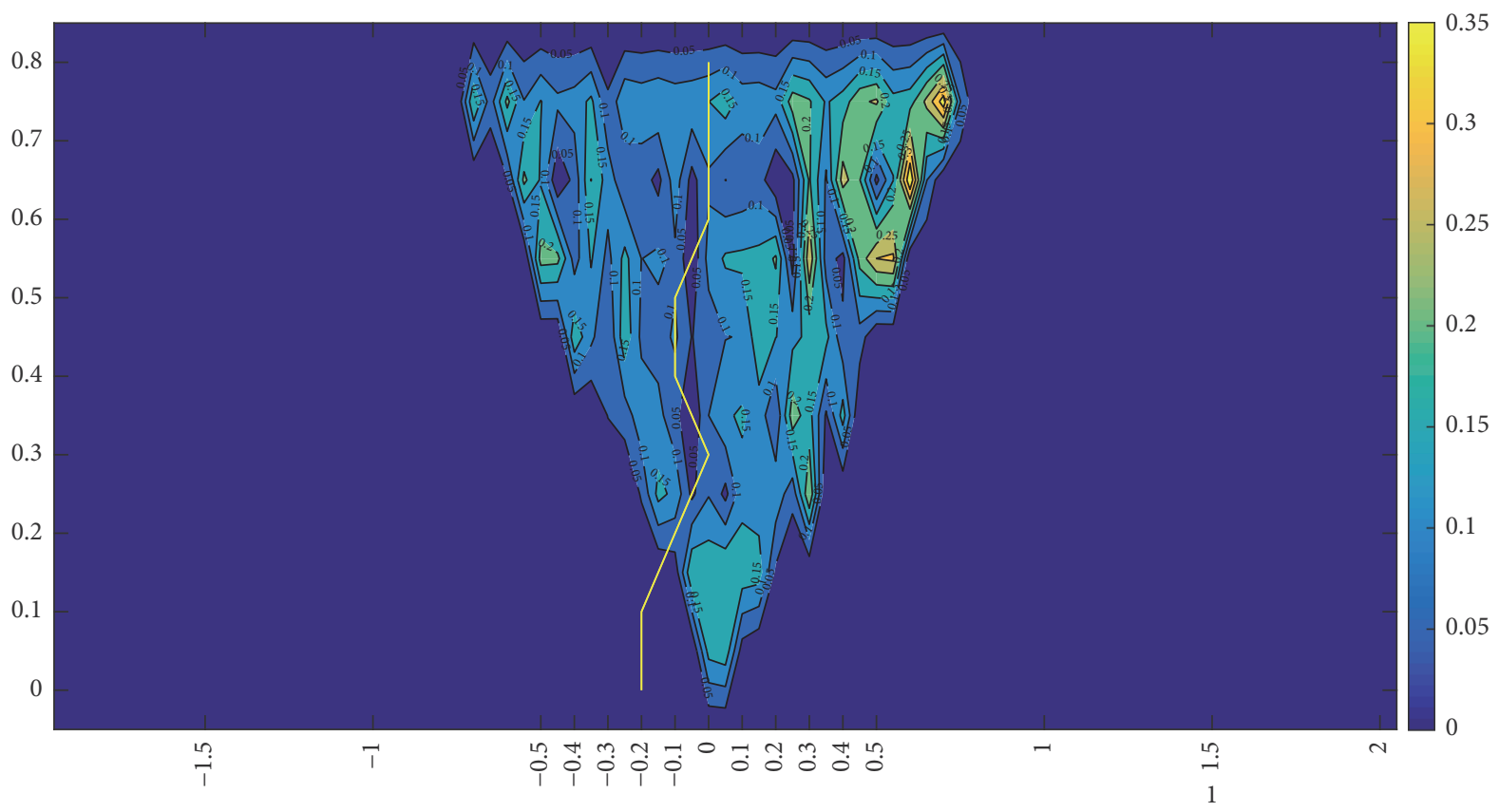

Path with Guidance factor

FIGURE 22: Optimal planning path.

\section{References}

[1] S.-M. Feng and G.-Q. Yin, "Transport route optimization model of dangerous goods at the planning level," Harbin Gongye Daxue Xuebao/Journal of Harbin Institute of Technology, vol. 44, no. 8, pp. 53-56, 2012.
[2] Z. Zhou, C. Li, J. Zhao, and W. Xu, "A real time path planning algorithm based on local complicated environment," Harbin Gongye Daxue Xuebao/Journal of Harbin Institute of Technology, vol. 46, no. 8, pp. 65-71, 2014.

[3] J. Zhuang, L. Zhang, H. Sun, and Y. Su, "Improved rapidlyexploring random tree algorithm application in unmanned 
surface vehicle local path planning," Harbin Gongye Daxue Xuebao/Journal of Harbin Institute of Technology, vol. 47, no. 1, pp. 112-117, 2015.

[4] F.-H. Jin, H.-J. Gao, and X.-J. Zhong, "Research on path planning of robot using adaptive ant colony system," Harbin Gongye Daxue Xuebao/Journal of Harbin Institute of Technology, vol. 42, no. 7, pp. 1014-1018, 2010.

[5] C. Chao, T. Jian, and J. Zuguang, "A path planning algorithm for seeing eye robots based on V-Graph [J]," Mechanical Science and Technology for Aerospace Engineering, vol. 33, no. 4, pp. 490495, 2014.

[6] Y. Huan, L. Naiwen, and D. Huichuan, "Research on topical Crawler of T-Graph algorithm," Computer Engineering and Design, vol. 35, no. 9, pp. 3014-3017, 2014.

[7] T. Wei, Research on path optimization of large scale logistics vehicle based on Voronoi graph, Wuhan University, Wuhan, China, 2013.

[8] W. Wang and H. Wang, "Real-time obstacle avoidance trajectory planning for missile borne air vehicle based on constrained artificial potential field method," Hangkong Dongli Xuebao/Journal of Aerospace Power, vol. 29, no. 7, pp. 1738-1743, 2014.

[9] Y. Jian and Y. Zhang, "Complete coverage path planning algorithm for mobile robot: Progress and prospect," Journal of Computer Applications, vol. 34, no. 10, pp. 2844-2849, 2014.

[10] R. A. Conn and M. Kam, "Robot motion planning on Ndimensional star worlds among moving obstacles," IEEE Transactions on Robotics and Automation, vol. 14, no. 2, pp. 320-325, 1998.

[11] E. Garcia-Fidalgo and A. Ortiz, "Vision-based topological mapping and localization methods: a survey," Robotics and Autonomous Systems, vol. 64, pp. 1-20, 2015.

[12] Z. Jiandong, Robot path planning based on narrow passage recognition, Shanghai Jiao Tong University, Shanghai, China, 2012.

[13] Y.-C. Yang, J.-S. Bao, and Y. Jin, "Realistic virtual lunar surface simulation method," Xitong Fangzhen Xuebao / Journal of System Simulation, vol. 19, no. 11, pp. 2515-2518, 2007.

[14] N. Tuygun, G. Tanir, and C. Aytekin, "Recurrent bacterial meningitis in children: our experience with 14 cases," The Turkish Journal of Pediatrics, vol. 52, no. 4, pp. 348-353, 2010.

[15] S. L. Laubach and J. W. Burdick, "Autonomous sensor-based path-planner for planetary microrovers," in Proceedings of the 1999 IEEE International Conference on Robotics and Automation, ICRA99, pp. 347-354, May 1999.

[16] C. Haiyuan, The research on ant colony algorithm of mobile robot path planning, Harbin Engineering University, 2013.

[17] R. Yue and S. Wang, "Path planning of a climbing robot using mixed integer linear programming," Beijing Hangkong Hangtian Daxue Xuebao/Journal of Beijing University of Aeronautics and Astronautics, vol. 39, no. 6, pp. 792-797, 2013.

[18] W. ZHANG, D. Zhaolong, and J. Yang, "Constructing methods for lunar digital terrain," in Abstracts of the Present Issue, vol. 25, pp. 301-306, 2008.

[19] M.-P. Shi, J. Wu, Y. Li, and H.-G. He, "A multi-constrained world modeling method in lunar rover path-planning," Guofang Keji Daxue Xuebao/Journal of National University of Defense Technology, vol. 28, no. 5, pp. 104-118, 2006.

[20] C. Chen, C. Bu, Y. He, and J. Han, "Environment modeling for long-range polar rover robots," Chinese Science Bulletin (Chinese Version), vol. 58, no. S2, pp. 75-85, 2013.
[21] P. Urcola, M. T. Lázaro, J. A. Castellanos, and L. Montano, "Cooperative minimum expected length planning for robot formations in stochastic maps," Robotics and Autonomous Systems, vol. 87, pp. 38-50, 2017.

[22] Y. Jianjian, T. Zhiwei, and W. Zirui, "Fault diagnosis on cutting unit of mine roadheader based on PSO-BP neural network," in Coal Science and Technology, vol. 45, pp. 129-134, 10 edition, 2017. 


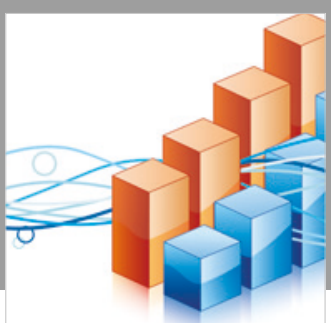

Advances in

Operations Research

\section{-n-m}
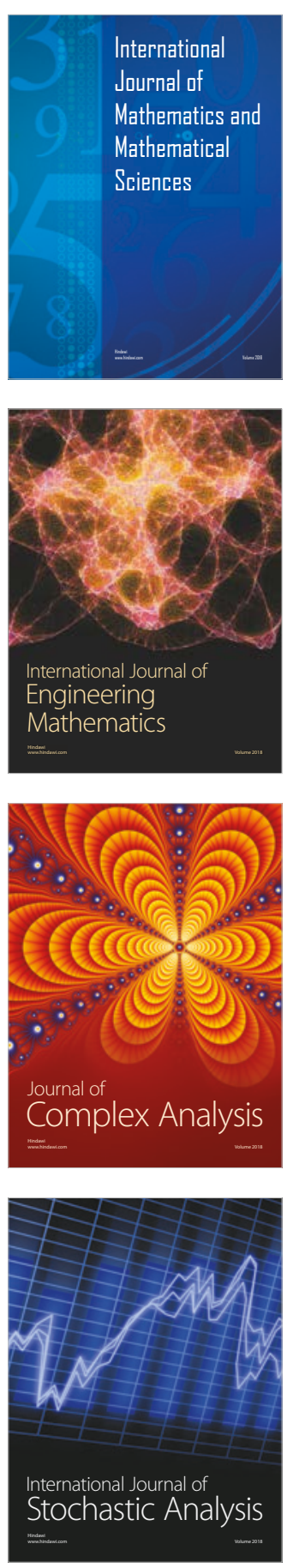
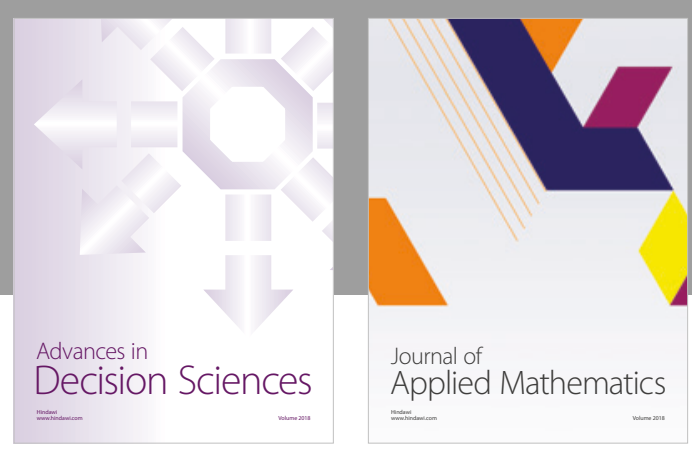

Journal of

Applied Mathematics
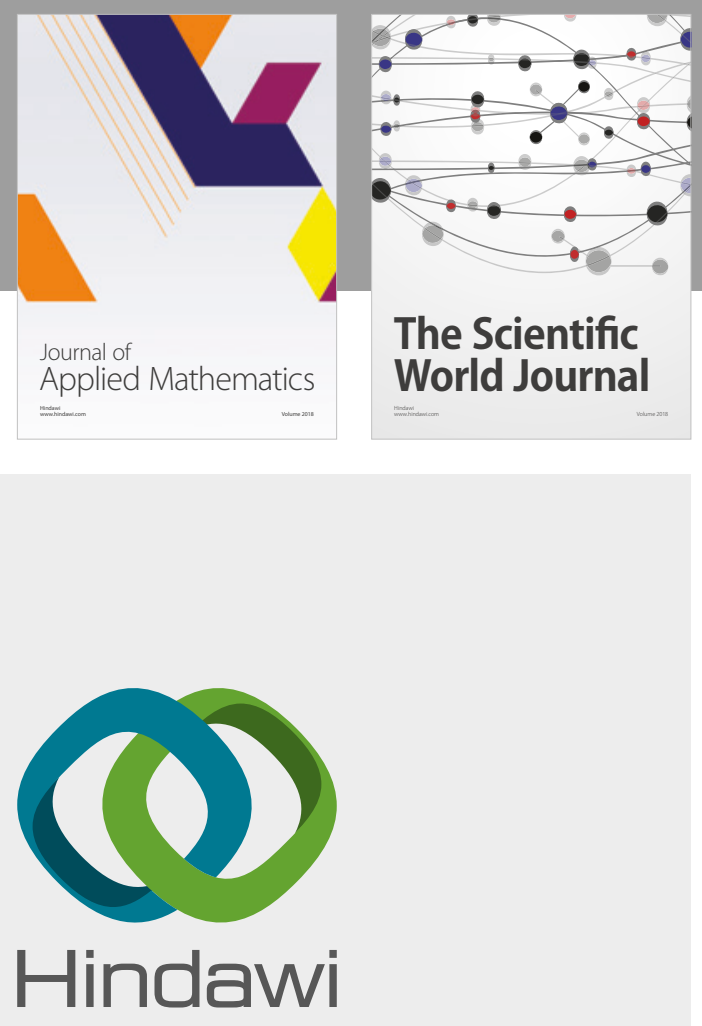

Submit your manuscripts at

www.hindawi.com

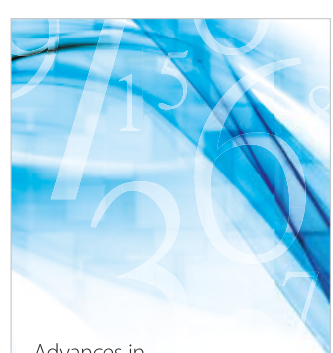

Advances in
Numerical Analysis
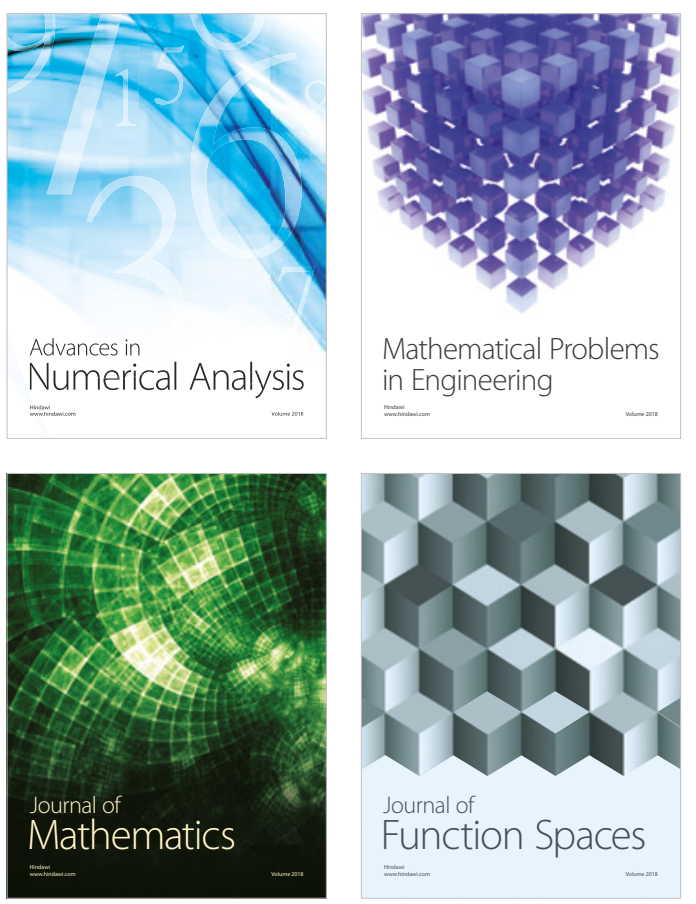

Mathematical Problems in Engineering

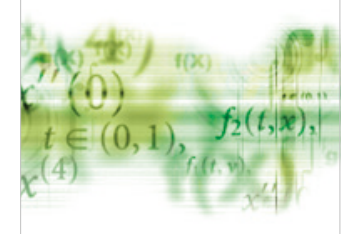

International Journal of

Differential Equations

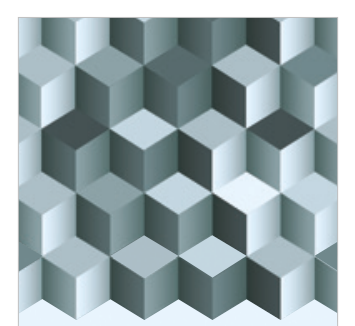

Journal of

Function Spaces

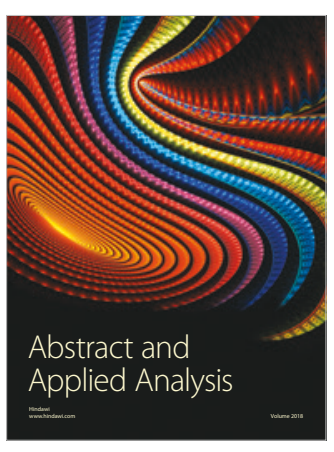

The Scientific

World Journal

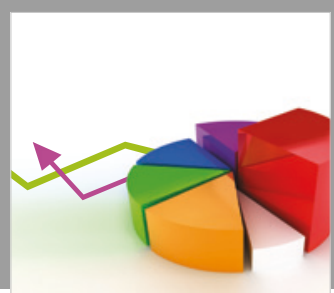

Journal of

Probability and Statistics
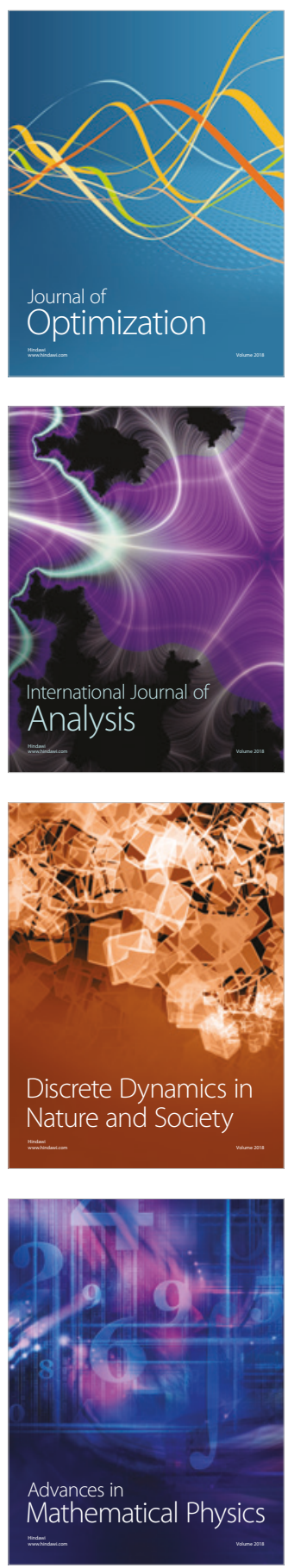